\title{
Critical serrated flow features during nanoindentation in La-based bulk metallic glasses
}

\author{
Wei Peng ${ }^{1)}$, Taihua Zhang ${ }^{2)}$, Yuan Liu $^{1)}$, Lei $L^{1)}$, and Bingchen Wei ${ }^{1)}$ \\ 1) National Microgravity Laboratory, Institute of Mechanics, Chinese Academy of Sciences, Beijing 100080, China \\ 2) State Key Laboratory of Nonlinear Mechanics (LNM), Institute of Mechanics, Chinese Academy of Sciences, Beijing 100080, China \\ (Received 2006-06-15)
}

\begin{abstract}
La}_{57.6} \mathrm{Al}_{17.5}(\mathrm{Cu}, \mathrm{Ni})_{24.9}$ and $\mathrm{La}_{64} \mathrm{Al}_{14}(\mathrm{Cu}, \mathrm{Ni})_{22}$ bulk metallic glasses (BMGs) were prepared by copper-mould casting method. Plastic deformation behavior of the two $\mathrm{BMGs}$ at various loading rates was studied by nanoindentation. The results showed that the $\mathrm{La}_{57.6} \mathrm{Al}_{17.5}(\mathrm{Cu}, \mathrm{Ni})_{24.9} \mathrm{BMG}$ with a glass transition temperature of $423 \mathrm{~K}$ exhibited prominent serrated flow at low loading rates, whereas less pronounced serrated flow at high rates during nanoindentation. In contrast, the $\mathrm{La}_{64} \mathrm{Al}_{14}(\mathrm{Cu}, \mathrm{Ni})_{22} \mathrm{BMG}$ with a glass transition temperature of $401 \mathrm{~K}$ exhibited prominent serrated flow at high loading rates. The different rate dependency of serrated flow in the two La-based BMGs is related to the different glass transition temperature, and consequently the degree of viscous flow during indentation at room temperature. A smoother flow occurs in the alloy with relatively lower glass transition temperature, due to the relaxation of stress concentration.
\end{abstract}

Key words: bulk metallic glass; nanoindentation; serrated flow; shear band

[This work was financially supported by the National Natural Science Foundation of China (No.50571109, 10572142 and 10432050) and the Knowledge Innovation Program of the Chinese Academy of Sciences.]

\section{Introduction}

The plastic deformation of bulk metallic glasses (BMGs) can be classified by either inhomogeneous or homogeneous deformation. Inhomogeneous deformation usually occurs at low temperatures (e.g. room temperature) or at a larger strain rates, and is characterized by the formation of localized shear bands, followed by their rapid propagation, and catastrophic fracture [1-2]. In constrained modes of loading (e.g., compression or indentation), global plastic deformation at room temperature is possible, where flow is typically found to be serrated [3-9]. Recently, nanoindentation experiments have increasingly being used to evaluate the mechanical response of metallic glasses, due to their superiority of the observation of the mechanisms of plastic deformation under wellcontrolled conditions [3-11]. Serrated flow during nanoindentation has been observed in $\mathrm{Pd}-, \mathrm{Zr}$-, La-, Nd-, $\mathrm{Mg}-$ and Cu-based BMGs, in which discrete displacement bursts (pop-ins) appear in the loading part of load-depth curves [3-11]. It has been found that the character of serrated flow depends on the composition and the structure of BMGs, as well as on the applied strain rate during nanoindentation measurements [3-
11]. The Pd-based alloys exhibit sharper displacement bursts than $\mathrm{Zr}$-based materials at the same loading rate $[3,8]$. Furthermore, Schuh and Nieh [4-5] found that serrated flow strongly depends on the indentation strain rate, with lower rates promoting more prominent serrations or displacement bursts. They constituted a new high-rate regime of homogeneous flow in the deformation map of metallic glasses, and suggest that there is a transition in plastic flow behavior in which serrations are suppressed at higher strain rates because of the dominance of shear band nucleation kinetics at high deformation rates [4-5]. The disappearance of serrations during nanoindentation at high strain rates was also observed in later works $[6,8,11]$. However, Greer et al. [12] have reported that such a transition does not actually occur, suggesting that the apparent absence of serrations is merely due to the lack of resolution at low depths, intensified by instrumental blurring at high loading rates. Obviously, a better understanding of these phenomena should be helpful to clarify the physical nature of shear bands.

In this work, the plastic deformation behavior of two La-based BMGs during nanoindentation was studied. The effect of loading rates on serrated flow 
features was also investigated. An anomalous rate dependency of serrated flow was observed in this alloy system.

\section{Experimental}

Ingots of $\mathrm{La}_{57.6} \mathrm{Al}_{17.5}(\mathrm{Cu}, \mathrm{Ni})_{24.9}$ and $\mathrm{La}_{64} \mathrm{Al}_{14}(\mathrm{Cu}$, $\mathrm{Ni}_{22}$ alloys were prepared by arc-melting the pure elements with purities ranging from $99.5 \%$ to $99.99 \%$ together under a purified argon atmosphere. Cylindrical rods of $3 \mathrm{~mm}$ in diameter were produced by chillcasting into a copper mold. The structure of the samples was characterized by X-ray diffraction (XRD) using $\mathrm{Cu} \mathrm{K}_{\mathrm{a}}$ radiation. Thermal analysis was performed with a Perkin-Elmer DSC 7 differential scanning calorimeter at a heating rate of $20 \mathrm{~K} / \mathrm{min}$ under argon atmosphere. Nanoindentation tests were conducted using an MTS Nano Indenter $\mathrm{XP}^{\mathrm{TM}}$ with a Berkovich diamond tip under a load control mode. The specimens were polished to mirror finish before measurements. The loading procedure consisted of five subsequent steps: (1) loading to a peak depth at a selected loading rate; (2) holding the load for $10 \mathrm{~s}$ at the peak depth; (3) unloading to $90 \%$ of the peak load at the rate same to the loading one; (4) holding load for $10 \mathrm{~s}$ for thermal drift calibration; (5) unloading completely. Four loading rates were used in the experiments $(0.075,0.2,0.5$, and $1 \mathrm{mN} / \mathrm{s})$. The thermal drift of the instrument was below $0.05 \mathrm{~nm} / \mathrm{s}$. At least six indentations were made for each test. All the tests were carried out at room temperature ( $293 \mathrm{~K})$.

\section{Results and discussion}

Fig. 1 shows the XRD patterns of the as-cast $\mathrm{La}_{57.6} \mathrm{Al}_{17.5}(\mathrm{Cu}, \mathrm{Ni})_{24.9}$ and $\mathrm{La}_{64} \mathrm{Al}_{14}(\mathrm{Cu}, \mathrm{Ni})_{22}$ alloys with 3- $\mathrm{mm}$ diameter. The specimens exhibit typical amorphous structure under the detection limit of XRD. The DSC results obtained at a heating rate of $20 \mathrm{~K} / \mathrm{min}$ for the as-cast $\mathrm{La}_{57.6} \mathrm{Al}_{17.5}(\mathrm{Cu}, \mathrm{Ni})_{24.9}$ and $\mathrm{La}_{64} \mathrm{Al}_{14}(\mathrm{Cu}, \mathrm{Ni})_{22}$ samples are exhibited in Fig. 2. The two alloys both show an endothermic reaction caused by glass transition, followed by an exothermic reaction caused by crystallization. The onset temperature of glass transition $\left(T_{\mathrm{g}}\right)$, the crystallization temperature $\left(T_{\mathrm{x}}\right)$, the width of supercooled liquid region $\left(\Delta T=T_{\mathrm{x}}-T_{\mathrm{g}}\right)$ and $T_{\mathrm{R}} / T_{\mathrm{g}}$ (where $T_{\mathrm{R}}$ is $293 \mathrm{~K}$ ) of the two BMGs are listed in Table 1. It can be seen that $T_{\mathrm{g}}$ and $T_{\mathrm{R}} / T_{\mathrm{g}}$ is $423 \mathrm{~K}$ and 0.69 respectively for $\mathrm{La}_{57.6} \mathrm{Al}_{17.5}(\mathrm{Cu}, \mathrm{Ni})_{24.9}$ alloy, while is $401 \mathrm{~K}$ and 0.73 respectively for $\mathrm{La}_{64} \mathrm{Al}_{14}(\mathrm{Cu}, \mathrm{Ni})_{22}$ alloy. These agree well with the reported results [13].

The load-displacement $(P-h)$ curves of $\mathrm{La}_{57.6} \mathrm{Al}_{17.5}(\mathrm{Cu}, \mathrm{Ni})_{24.9}$ and $\mathrm{La}_{64} \mathrm{Al}_{14}(\mathrm{Cu}, \mathrm{Ni})_{22}$ BMGs during nanoindentation at various loading rates are presented in Fig. 3. The origin of each curve is displaced for clearer observation. It can be seen that the maximum load at the indentation depth of $1000 \mathrm{~nm}$ increases with increasing the loading rate for both $\mathrm{La}_{57.6} \mathrm{Al}_{17.5}(\mathrm{Cu}, \mathrm{Ni})_{24.9}$ (Fig. 3(a)) and $\mathrm{La}_{64} \mathrm{Al}_{14}(\mathrm{Cu}, \mathrm{Ni})_{22}$ (Fig. 3(b)) BMGs. This means that the hardness of the two La-based BMGs strongly depends on the loading rate (Table 2), and increases gradually from $2.63 \mathrm{GPa}$ at $0.075 \mathrm{mN} / \mathrm{s}$ to $2.89 \mathrm{GPa}$ at $1.0 \mathrm{mN} / \mathrm{s}$ for $\mathrm{La}_{57.6} \mathrm{Al}_{17.5}(\mathrm{Cu}, \mathrm{Ni})_{24.9}$, while $1.98 \mathrm{GPa}$ at $0.075 \mathrm{mN} / \mathrm{s}$ to $2.23 \mathrm{GPa}$ at $1.0 \mathrm{mN} / \mathrm{s}$ for $\mathrm{La}_{64} \mathrm{Al}_{14}(\mathrm{Cu}, \mathrm{Ni})_{22}$ alloy respectively. It can also be observed in Fig. 3 that, during the hold segment for $10 \mathrm{~s}$ at the maximum load, a creep deformation occurs in $\mathrm{La}_{64} \mathrm{Al}_{14}(\mathrm{Cu}, \mathrm{Ni})_{22}$ alloy, which is more prominent at higher loading rates (about $20 \mathrm{~nm}$ at $1.0 \mathrm{mN} / \mathrm{s}$ ). However, no prominent creep is found in $\mathrm{La}_{57.6} \mathrm{Al}_{17.5}(\mathrm{Cu}, \mathrm{Ni})_{24.9}$ alloy at all loading rates.

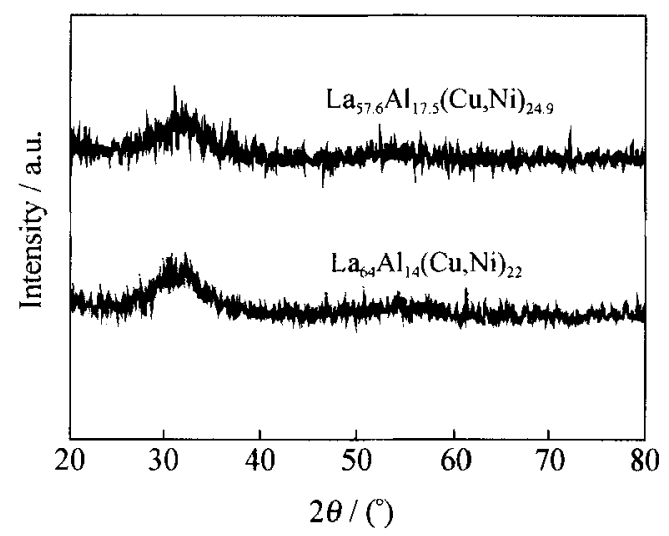

Fig. 1. XRD patterns for the as-cast $\mathrm{La}_{57.6} \mathrm{Al}_{17.5}(\mathrm{Cu}, \mathrm{Ni})_{24.9}$ and $\mathrm{La}_{64} \mathrm{Al}_{14}(\mathrm{Cu}, \mathrm{Ni})_{22}$ BMGs rods.

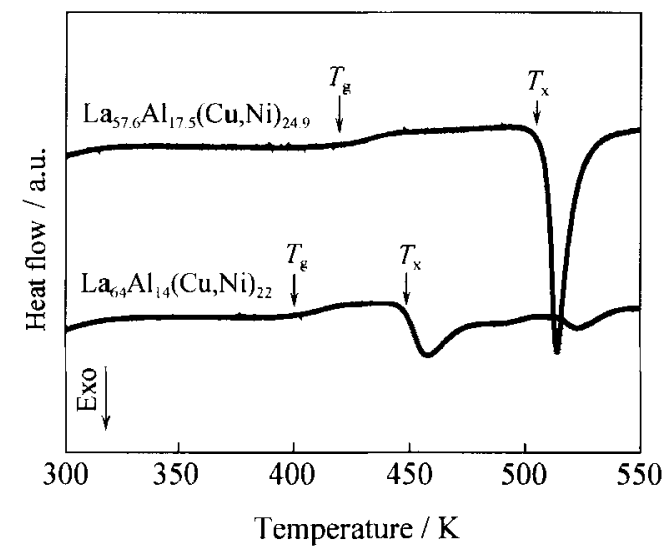

Fig. 2. DSC curves for the $\mathrm{La}_{57.6} \mathrm{Al}_{17.5}(\mathrm{Cu}, \mathrm{Ni})_{24.9}$ and $\mathrm{La}_{64} \mathrm{Al}_{14}(\mathrm{Cu}, \mathrm{Ni})_{22} \mathrm{BMGs}$ at a heating rate of $20 \mathrm{~K} / \mathrm{min}$.

It should be noted that the deformation behavior of the two BMGs strongly depends on the indentation loading rate, as shown in the loading parts of the $P-h$ curves in Fig. 3. The $\mathrm{La}_{57.6} \mathrm{Al}_{17.5}(\mathrm{Cu}, \mathrm{Ni})_{24.9}$ BMG exhibits a few strong serrations at low loading rates and many weak serrations at high loading rates (Fig. 3a). In contrast, the $\mathrm{La}_{64} \mathrm{Al}_{14}(\mathrm{Cu}, \mathrm{Ni})_{22}$ BMG exhibits a 
smooth loading curve at low rates, whereas strong serrations at high rates. The threshold loading rate value for the appearance of the serrated flow during indentation is about $0.2 \mathrm{mN} / \mathrm{s}$.

Table 1. Results of DSC measurements for $\mathrm{La}_{57.6} \mathrm{Al}_{17.5}(\mathrm{Cu}, \mathrm{Ni})_{24.9}$ and $\mathrm{La}_{64} \mathrm{Al}_{14}(\mathrm{Cu}, \mathrm{Ni})_{22} \mathrm{BMGs}$ at a heating rate of $20 \mathrm{~K} / \mathrm{min}$

\begin{tabular}{ccccc}
\hline Alloy & $T_{\mathrm{g}} / \mathrm{K}$ & $T_{\mathrm{x}} / \mathrm{K}$ & $\Delta T=T_{\mathrm{x}}-T_{\mathrm{g}} / \mathrm{K}$ & $T_{\mathrm{R}} / T_{\mathrm{g}}$ \\
\hline $\mathrm{La}_{57.6} \mathrm{Al}_{17.5}(\mathrm{Cu}, \mathrm{Ni})_{24.9}$ & 423 & 512 & 89 & 0.69 \\
$\mathrm{La}_{64} \mathrm{Al}_{14}(\mathrm{Cu}, \mathrm{Ni})_{22}$ & 401 & 449 & 48 & 0.73 \\
\hline
\end{tabular}
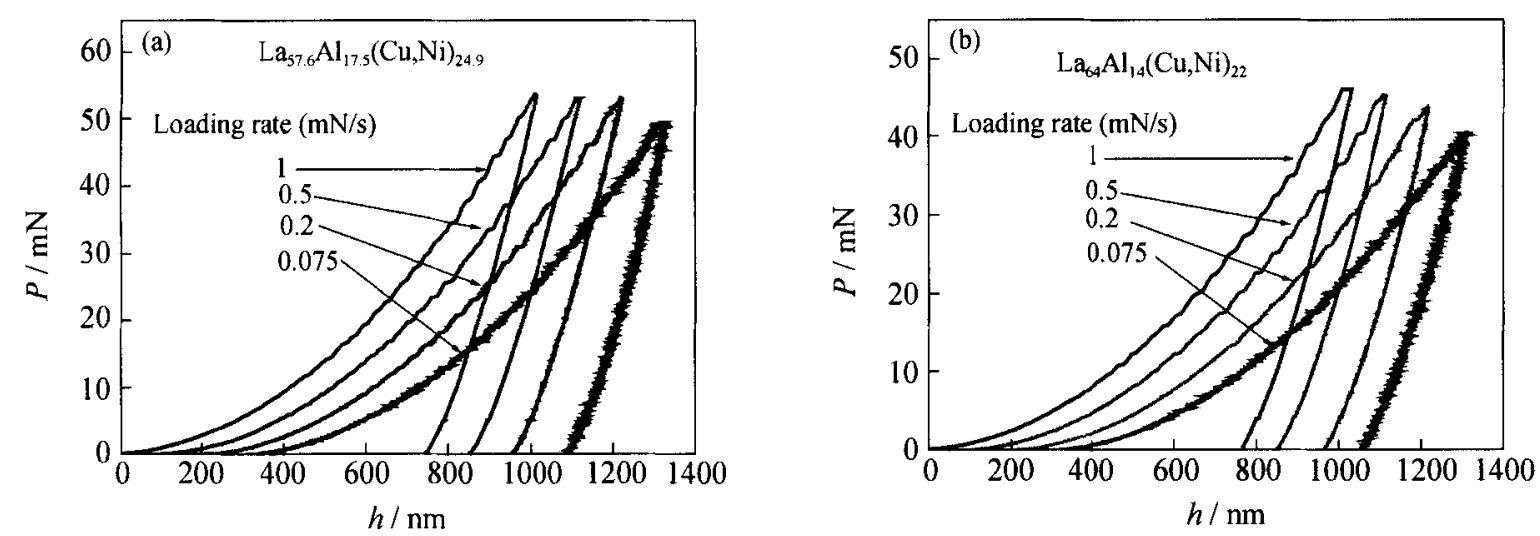

Fig. 3. Typical load-displacement $(P-h)$ curves during nanoindentation at various loading rates for $\mathrm{La}_{57.6} \mathrm{Al}_{17.5}(\mathrm{Cu}, \mathrm{Ni})_{24.9}(\mathrm{a})$ and $\mathrm{La}_{64} \mathrm{Al}_{14}(\mathrm{Cu}, \mathrm{Ni})_{22}$ (b) BMGs.

Table 2. Hardness of $\mathrm{La}_{57.6} \mathrm{Al}_{17.5}(\mathrm{Cu}, \mathrm{Ni})_{24.9}$ and $\mathrm{La}_{64} \mathrm{Al}_{14}(\mathrm{Cu}, \mathrm{Ni})_{22} \mathrm{BMGs}$ at various loading rates

\begin{tabular}{ccc}
\hline Loading Rate $/\left(\mathrm{mN} \cdot \mathrm{s}^{-1}\right)$ & $\mathrm{La}_{57.6} \mathrm{Al}_{17.5}(\mathrm{Cu}, \mathrm{Ni})_{24.9}$ & $\mathrm{La}_{64} \mathrm{Al}_{14}(\mathrm{Cu}, \mathrm{Ni})_{22}$ \\
\hline 0.075 & 2.63 & 1.98 \\
0.2 & 2.76 & 2.09 \\
0.5 & 2.80 & 2.23 \\
1 & 2.89 & 2.27 \\
\hline
\end{tabular}

To further characterize the serrated flow in the loaddisplacement curves of the two BMGs during nanoindentation at various loading rates, the amplitude of the serrations is chosen to express the features of the serrations. The displacement plotted as a function of the load at various loading rates was simulated as exponential function:

$h_{\mathrm{fit}}=C P^{m}$

where $h_{\mathrm{fit}}$ is the simulated value of displacement, $P$ the load value, $C$ and $m$ are constants. The amplitude of the serrations, $\Delta h$, is defined as

$\Delta h=h_{\exp }-h_{\text {fit }}$

where $h_{\text {exp }}$ is the experimental value. Fig. 4 shows the $\Delta h$ - $h$ curves for $\mathrm{La}_{57.6} \mathrm{Al}_{17.5}(\mathrm{Cu}, \mathrm{Ni})_{24.9}$ and $\mathrm{La}_{64} \mathrm{Al}_{14}(\mathrm{Cu}$, $\mathrm{Ni})_{22}$ BMGs during nanoindentation at various loading rates. It can be seen that a few serrations with large $\Delta h$ occur during the loading process at the lowest rate of $0.075 \mathrm{mN} / \mathrm{s}$, while a larger number of serrations with smaller $\Delta h$ appear at higher rates in the $\mathrm{La}_{57.6} \mathrm{Al}_{17.5}(\mathrm{Cu}, \mathrm{Ni})_{24.9}$ BMG (Fig. 4(a)). For the $\mathrm{La}_{64} \mathrm{Al}_{14}(\mathrm{Cu}, \mathrm{Ni})_{22} \mathrm{BMG}$, the number and size of serrations both increase with increasing the loading rate
(Fig. 4(b)).

Fig. 5 shows the SEM images of the typical surface deformation features obtained after nanoindentation at various loading rates. It can be seen that though the deformation behavior of the two BMGs varies strongly with the chemical composition and the applied loading rate, no obvious circular patterns can be observed around the indents for the two alloys at all the studied loading rates.

The deformation feature of the $\mathrm{La}_{57.6} \mathrm{Al}_{17.5}(\mathrm{Cu}$, $\mathrm{Ni}_{24.9}$ BMG during nanoindentation in this study is consistent with that of other BMG systems, e.g. Zr-, $\mathrm{Pd}-, \mathrm{Cu}-, \mathrm{La}-$, and $\mathrm{Mg}$-based BMGs, for which a low indentation rate promotes more pronounced serrations, and rapid indentation suppresses serrated flow [3-10]. The serrated flow is related to the formation and propagation of shear bands during plastic deformation [1-2]. The disappearance of prominent serrated flow at high rates was supposed to be the simultaneous operation of multiple shear bands to accommodate to rapid plastic deformation, though the increase of the number of serrations at high loading rates is not found in the $P-h$ curves. However, the $P-h$ curves of the 
$\mathrm{La}_{57.6} \mathrm{Al}_{17.5}(\mathrm{Cu}, \mathrm{Ni})_{24.9}$ BMG clearly show that the number of serrations increase significantly with the loading rate (Figs. 3(a) and 4(a)). This gives a direct

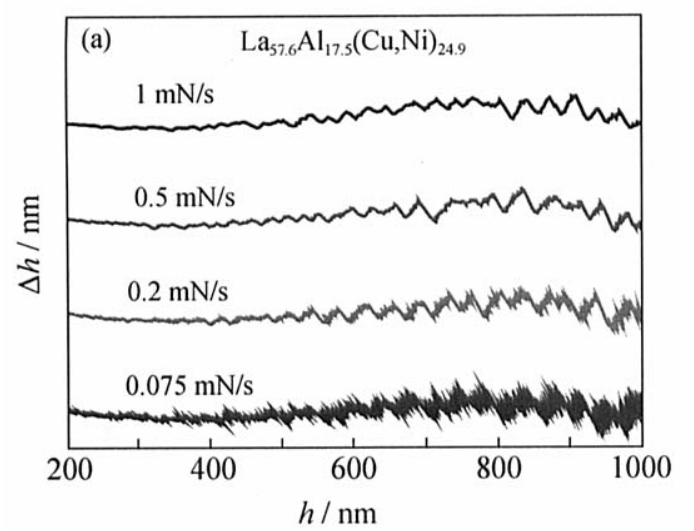

proof for the operation of multiple shear bands at high rates.

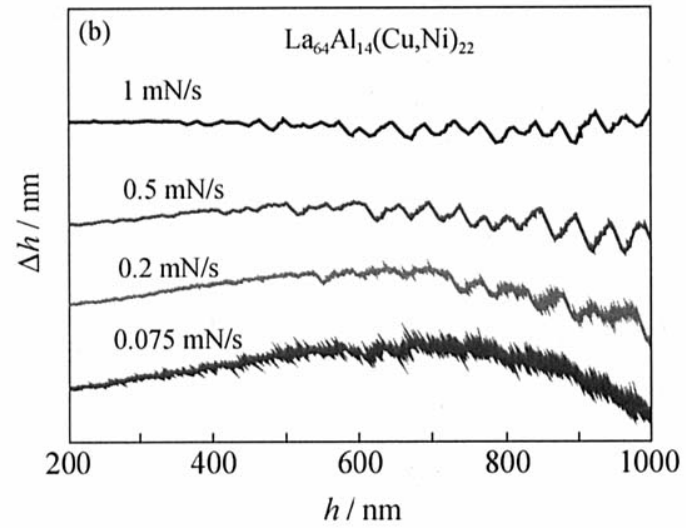

Fig. 4. $\Delta h$ - $h$ curves for $\mathrm{La}_{57.6} \mathrm{Al}_{17.5}(\mathrm{Cu}, \mathrm{Ni})_{24.9}$ (a) and $\mathrm{La}_{64} \mathrm{Al}_{14}(\mathrm{Cu}, \mathrm{Ni})_{22}$ (b) BMGs during nanoindentation at various loading rates.
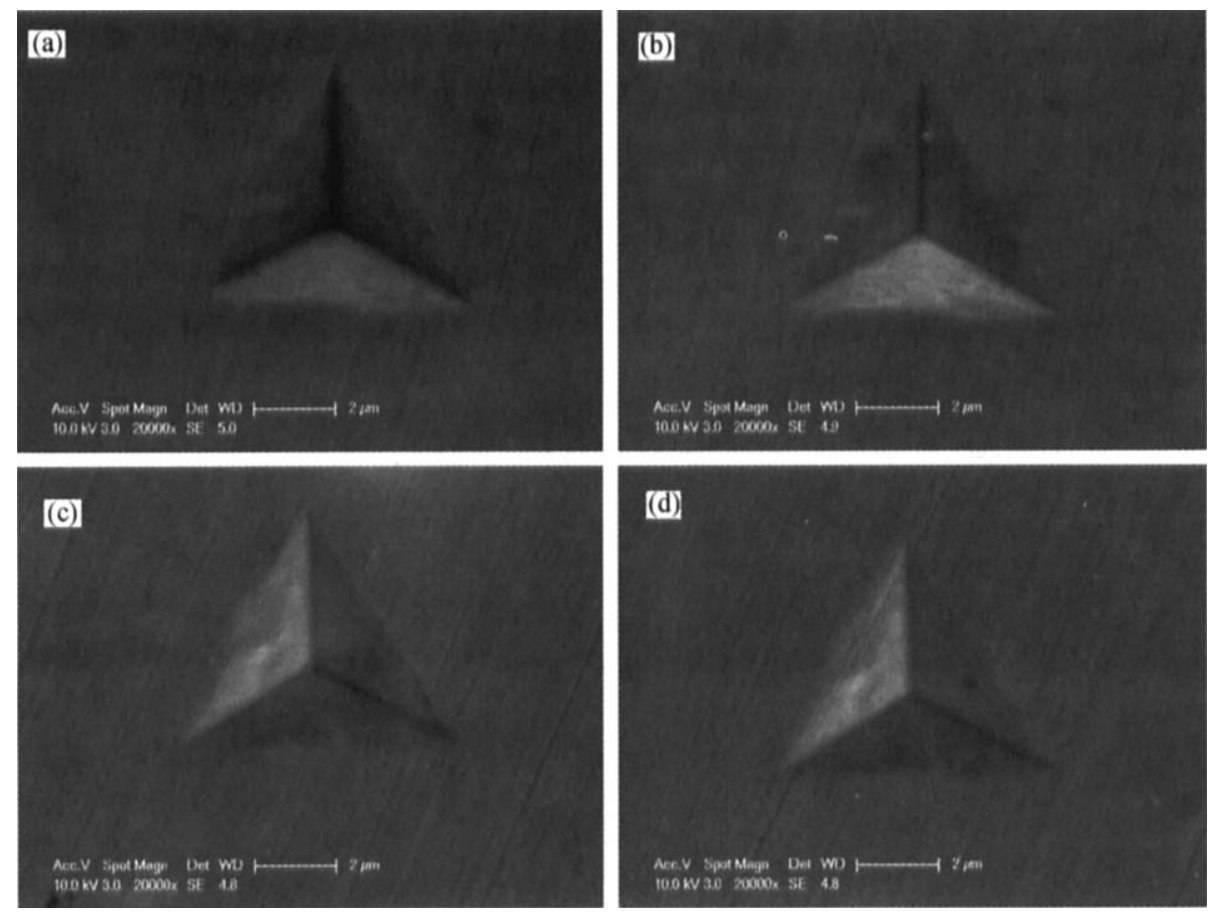

Fig. 5. SEM images of the typical surface deformation features around the indents after nanoindentation measurements for the two BMGs at various loading rates: (a) $\mathrm{La}_{57.6} \mathrm{Al}_{17.5}(\mathrm{Cu}, \mathrm{Ni})_{24.9}$ at $0.075 \mathrm{mN} / \mathrm{s} ;$ (b) $\mathrm{La}_{57.6} \mathrm{Al}_{17.5}(\mathrm{Cu}, \mathrm{Ni})_{24.9}$ at $1 \mathrm{mN} / \mathrm{s} ;(\mathrm{c})$ $\mathrm{La}_{64} \mathrm{Al}_{14}(\mathrm{Cu}, \mathrm{Ni})_{22}$ at $0.075 \mathrm{mN} / \mathrm{s}$; (d) $\mathrm{La}_{64} \mathrm{Al}_{14}(\mathrm{Cu}, \mathrm{Ni})_{22}$ at $1 \mathrm{mN} / \mathrm{s}$.

It should be noted that the $\mathrm{La}_{64} \mathrm{Al}_{14}(\mathrm{Cu}, \mathrm{Ni})_{22}$ BMG exhibits an anomalous rate dependency of serrated flow during nanoindentation, wherein a smooth deformation occurs at low loading rates and prominent serrated flow appears at high rates (Figs. 3(b) and 4(b)). The two La-based BMGs studied here are similar in chemical composition. The different deformation behavior during nanoindentation may be related to the difference in $T_{\mathrm{g}}$ of the two alloys. As seen in Fig. 2 and Table $1, T_{\mathrm{g}}$ and $T_{\mathrm{R}} / T_{\mathrm{g}}$ is $423 \mathrm{~K}$ and 0.69 respectively for the $\mathrm{La}_{57.6} \mathrm{Al}_{17.5}(\mathrm{Cu}, \mathrm{Ni})_{24.9} \mathrm{BMG}$, and is $401 \mathrm{~K}$ and 0.73 respectively for the latter BMG. It is generally accepted that the deformation mechanism of met- allic glasses depends both on the testing temperature and applied strain rate, and homogeneous deformation normally occurs at the temperature higher than $0.7 T_{\mathrm{g}}$ for quasi-static tensile or compressive tests [14]. The deformation behavior of BMGs near $T_{\mathrm{g}}$ can be Newtonian or non-Newtonian viscous flow, depending upon testing temperature and strain rate [15-16]. The $T_{\mathrm{R}} / T_{\mathrm{g}}$ of $\mathrm{La}_{64} \mathrm{Al}_{14}(\mathrm{Cu}, \mathrm{Ni})_{22}$ BMG is 0.73 . This means that the viscous flow may contribute to the plastic deformation at room temperature, which is proved by the appearance of creep during nanoindentation (Fig. 3(b)). The time-dependent creep is suppressed during rapid loading and occurs mainly during the load- 
holding segment, whereas at low loading rates, creep occurs also during the loading process, which is proved by the lower average slope of the loading curves. The creep deformation is related to the localized viscous flow, and is thought to strongly affect the deformation behavior of the BMG. The appearance of serrated flow is caused by the sudden release of elastic stress around the shear band due to the propagation of a single shear band. The viscous flow in the $\mathrm{La}_{64} \mathrm{Al}_{14}(\mathrm{Cu}, \mathrm{Ni})_{22}$ BMG during nanoindentation will relax the elastic stress around the shear bands, and consequently produce a smoother $P$ - $h$ curve at low loading rates. In contrast, at high loading rates, the viscous flow is suppressed, therefore the propagation of shear bands leads to a strong serration due to rapid release of elastic stress around the shear bands. As for the $\mathrm{La}_{57.6} \mathrm{Al}_{17.5}(\mathrm{Cu}, \mathrm{Ni})_{24.9}$ BMG, $T_{\mathrm{R}} / T_{\mathrm{g}}$ value is 0.69 . The contribution of viscous flow to the plastic deformation is much less than that in the $\mathrm{La}_{64} \mathrm{Al}_{14}(\mathrm{Cu}, \mathrm{Ni})_{22}$ BMG due to the relatively higher $T_{\mathrm{g}}$ for the former alloy. This is proved by the small creep displacement during nanoindentation in the former alloy (Fig. 3). Therefore, serrations with large size form during nanoindentation because of the stress release around shear bands. At higher loading rates, the contribution of viscous flow is neglectable, and simultaneous operation of multiple shear bands leads to less prominent serrated flow during nanoindentation.

\section{Conclusions}

Plastic deformation behavior of $\mathrm{La}_{57.6} \mathrm{Al}_{17.5}(\mathrm{Cu}$, $\mathrm{Ni})_{24.9}$ and $\mathrm{La}_{64} \mathrm{Al}_{14}(\mathrm{Cu}, \mathrm{Ni})_{22}$ BMGs was studied using nanoindentation. The two BMGs both exhibit a loading rate dependent hardness and creep during indentation. However, they exhibit different rate dependency of serrated flow features. The $\mathrm{La}_{57.6} \mathrm{Al}_{17.5}(\mathrm{Cu}, \mathrm{Ni})_{24.9}$ BMG shows prominent serrated flow at low loading rates and less pronounced serrated flow at high rates during nanoindentation, whereas the $\mathrm{La}_{64} \mathrm{Al}_{14}(\mathrm{Cu}, \mathrm{Ni})_{22}$ BMG exhibits a smooth loading curve at low rates and pronounced serrated flow at high rates. The different serrated flow feature in the two BMGs is ascribed to their difference in $T_{\mathrm{g}}$, and consequently the contribution of viscous flow to the plastic deformation. The load-displacement curves of the two BMGs at various loading rates give a direct evidence for the simultaneous operation of multiple shear bands at high loading rates.

\section{References}

[1] F. Spaepen, A microscopic mechanism for steady state in- homogeneous flow in metallic glasses, Acta Metall. 25(1977), p. 25.

[2] A. S. Argon, Plastic deformation in metallic glasses, Acta Metall. 27(1979), p.27.

[3] W.J. Wright, R. Saha, and W.D. Nix, Deformation mechanisms of the $\mathrm{Zr}_{40} \mathrm{Ti}_{14} \mathrm{Ni}_{10} \mathrm{Cu}_{12} \mathrm{Be}_{24}$ bulk metallic glass, Mater. Trans., 42(2001), p.642.

[4] C.A. Schuh and T.G. Nieh, A Survey of instrumented indentation studies on metallic glasses, J. Mater. Res., 19(2004), p.64.

[5] C.A. Schuh, A.C. Lund, and T.G. Nieh, New regime of homogeneous flow in the deformation map of metallic glasses: elevated temperature nanoindentation experiments and mechanistic modeling, Acta Mater., 52(2004), p.5879.

[6] G.P. Zhang, W. Wang, B. Zhang, J. Tan, and C.S. Liu, On rate-dependent serrated flow behavior in amorphous metals during nanoindentation, Scripta Mater., 52(2005), p.1147.

[7] W.H. Jiang, F.E. Pinkerton, and M. Atzmon, Mechanical behavior of shear bands and the effect of their relaxation in a rolled amorphous Al-based alloy, Acta Mater., 53(2005), p.3469.

[8] B.C. Wei, T.H. Zhang, W.H. Li, Y.F. Sun, Y. Yu, and Y.R. Wang, Serrated plastic flow during nanoindentation in Ndbased bulk metallic glasses, Intermetallics, 12(2004), p.1239.

[9] W.H. Li, T.H. Zhang, D.M. Xing, B.C. Wei, Y.R. Wang, and Y.D. Dong, Instrumented indentation study of plastic deformation in bulk metallic glasses, J. Mater. Res., 21(2006), p.75.

[10] J.J. Kim, Y. Choi, S. Suresh, and A.S. Argon, Nanocrystallization during nanoindentation of a bulk amorphous metal alloy at room temperature, Science, 295(2002) p.654.

[11] A. Concustell, J. Sort, G. Alcala, S. Mato, A. Gebert, J. Eckert, and M.D. Baro, Plastic deformation and mechanical softening of $\mathrm{Pd}_{40} \mathrm{Cu}_{30} \mathrm{Ni}_{10} \mathrm{P}_{20}$ bulk metallic glass during nanoindentation, J. Mater. Res., 20(2005) p.2719.

[12] A.L. Greer, A. Castellero, S.V. Madge, I.T. Walker, and J.R. Wilde, Nanoindention studies of shear banding in fully amorphous and partially devitrified metallic alloys, Mater. Sci. Eng. A, 357-377(2004), p.1185.

[13] H. Tan, Y. Zhang, D. Ma, Y.P. Feng, and Y. Li, Optimum glass formation at off-eutectic composition and its relation to skewed eutectic coupled zone in the La-based La-Al(Cu, Ni) pseudo ternary system, Acta Mater., 51(2003), p.4556.

[14] T.G. Nieh, C.A. Schuh, J. Wadsworth, and Y. Li, Strain rate-dependent deformation in bulk metallic glasses, $I n$ termetallics, 10(2002), p.1178.

[15] T.G. Nieh, J. Wadsworth, C.T. Liu, Y. Ohkubo, and Y. Hirotsu, Plasticity and structure instability in a bulk metallic glass deformed in the supercooled liquid region, Acta Mater., 49(2001), p.2887.

[16] Y. Kawamura, Y. Nakamura, and A. Inoue, Superplasticity in $\mathrm{Pd}_{40} \mathrm{Ni}_{40} \mathrm{P}_{20}$ metallic glass, Scripta Mater., 39(1998), p.301. 